\title{
A Política Externa Americana e seus críticos
}

\author{
American Foreign Politics and its critics
}

IVANI VASSOLER FROELICH*

Rev. Bras. Polít. Int. 48 (2): 205-215 [2005]

\section{Introdução}

A Teoria da Estabilidade Hegemônica que, entre outras suposições, enfatiza a necessidade do país dominante do cenário internacional em se impor em uma ordem mundial, é o ponto de partida para uma compreensão mais abrangente de várias análises feitas recentemente nos Estados Unidos, as quais questionam os rumos e as consequências da política exterior americana, a partir dos atentados de 11 de Setembro de 2001, em Nova York e Washington ${ }^{1}$ e, posteriormente, com a guerra no Iraque, iniciada em março de 2003.

Entre os questionamentos mais influentes nessa corrente crítica, de cunho reformista, estão os de dois acadêmicos que ocuparam postos relevantes nos centros de tomada de decisão, em Washington. Um deles é Zbigniew Brzezinski ${ }^{2}$, ex-conselheiro de Segurança Nacional da Casa Branca na presidência de Jimmy Carter, autor de vários livros sobre política exterior, e atualmente, professor de Relaçóes Internacionais na Universidade Johns Hopkins. O outro é o cientista político Joseph $\mathrm{Nye}^{3}{ }^{3}$ acadêmico da Universidade Harvard, escritor prolífico e ex-subsecretário de Defesa no governo Carter, e de Estado, durante o primeiro mandato do presidente Bill Clinton. Ao lidar com os conceitos de liderança e dominação que, por um lado são as duas imagens e práticas da política externa dos Estados Unidos, e que por outro, constituem o aspecto polêmico da Teoria da Estabilidade Hegemônica, tas análises alertam para os riscos de uma estratégia de governo predominantemente baseada no unilateralismo e no militarismo.

\footnotetext{
* Professora e pesquisadora no Deparmento de Ciênicas Políticas da State University of New York (ivani.vassoler-froelich@fredonia.edu).

${ }^{1}$ Vale a pena recordar que no mesmo evento, um dos aviōes sequestrados acabou caindo no Estado da Pensilvânia provocando a morte de todos os ocupantes. As investigaçóes revelaram que durante o vôo alguns passageiros enfrentaram os sequestradores, e que a aeronave ficou sem controle.

2 BRZEZINSKI, Zbigniew. The Choice: Global Domination or Global Leadership. New York: Basic Books, 2004.

${ }^{3}$ NYE, Joseph. The Paradox of American Power: Why the World's Only Superpower Can't Go It Alone. Oxford and New York: Oxford University Press. 2003; e Soft Power: The Means to Success in World Politics. New York: Public Affairs Press, 2004.
} 
Articulada por Charles Kindleberger, ${ }^{4}$ a Teoria da Estabilidade Hegemônica serve como fundamento para as análises de Brzezinski e Nye, já que ambos corroboram a mais relevante suposição daquele marco teórico: um poder hegemônico é necessário para assegurar um certo nível de ordem no sistema internacional, em virtude da capacidade de reduzir conflitos entre países e deter Estados agressores. ${ }^{5} \mathrm{E}$ na ausência de um poder hegemônico, o sistema entraria em caos. Transpondo a teoria para a realidade política internacional, Brzenzinski, por exemplo, destaca que o poder dos Estados Unidos é a fonte fundamental da segurança global. Entretanto, ele urge os americanos a pesarem as diferenças entre liderança e dominação, advertindo sobre o perigo de se confundir poderio com onipotência. Esta última prevalecendo, segundo ele, levaria o mundo a uma calamidade, deixando os Estados Unidos encurralados.

Interessados, portanto, em manter a hegemonia dos Estados Unidos no cenário internacional e partindo da pressuposição que o poder americano é um componente indispensável para a manutençao da segurança internacional, os autores, entretanto, colocam sérias objeções à atual política exterior conduzida por Washington, classificando-a como estreita, excessivamente obcecada com segurança interna, cega aos riscos da utilização do uso da força militar unilateral e indiferente às preocupações que afligem outras partes do mundo. Nesse quadro, ambos vêem nesses ingredientes uma receita para o desastre, argumentando que a única superpotência global seria melhor servida, em termos da manutenção do poder e da defesa dos próprios interesses, se recorresse a outros instrumentos na condução da política exterior.

Brzezinski desenvolve uma fómula, para o que ele chama de "política externa sábia”, a qual sem abrir mão do poder militar, tem também como prioridade a necessidade de cooperação entre os Estados Unidos e aliados para a promoção do bem comum, o que implica um compartamento externo pautado pela sensibilidade diante do sofrimento dos demais. Nye, por sua vez, sustenta que a melhor opção para nação americana é permanecer na posição de superpotência global, sem, entretanto, alienar o resto do mundo. Este vem se destacando nos últimos anos, como um dos defensores da necessidade de uma mudança de rumo na política externa americana. Em certo sentido, com argumentos similares ao de Brzezinski, especialmente no tocante à relevância da cooperação internacional, Nye é, entretanto, inovador ao introduzir o conceito de soft power (poder suave) em oposição ao hard power, o poder duro, que caracteriza atualmente muitas das ações americanas no exterior, representado pela prioridade dada às intervençôes militares em detrimento de outros

\footnotetext{
${ }^{4}$ KINDLEBERGER, Charles. The World in Depression - 1929-39. Berkeley: University of California Press, 1973. O argumento do autor foi desenvolvido a partir do caos internacional gerado pela crise de 1929, a Grande Depressão.

5 GOLDSTEIN, Joshua \& PEVEHOUSE, Jon. International Relations. New York: Pearson/Longman, 2006. p. 66.
} 
instrumentos, particularmente à diplomacia pública, para a obtenção de objetivos internacionais.

Como superpotência, os Estados Unidos contam com ambos poderes em abudância: um poderio militar incontestável (hard power), e assim detentor uma capacidade inigualável de coação; e também, com uma variedade de instrumentos de persuasão, sem uso da força (soft power), entre eles, a diplomacia pública (incluindo a concessão de bolsas de estudo para estrangeiros, os programas de intercâmbio cultural entre acadêmicos, a mídia financiada pelo Estado, como "A Voz da América", e a atividade de órgãos do governo, encarregados das relações públicas no exterior). Todas essas ações funcionam como canais para a disseminação, no exterior, do objetivo americano declarado em promover a expansão da democracia representativa liberal. Esta última é considerada uma das pedras fundamentais para a manutenção da estabilidade e da segurança internacional, sempre tão almejadas pelo poder hegemônico atual e do passado, como o caso do Império Romano, que impôs uma ordem mundial, a chamada Pax Romana, na qual o poder imperial foi mantido graças à pacificação das províncias. Outras ferramentas do poder suave se manifestam por meio do comércio internacional e da ajuda financeira aos países pobres, dois elementos que sustentam outros importantes objetivos da superpotência, sendo eles, o avanço das economias de mercado e o fortalecimento do capitalismo. Junto com a democracia liberal, a prosperidade econômica global fundamentada no capitalismo, é considerada a outra pedra fundamental para garantir a segurança e estabilidade mundial, nos moldes da ordem buscada pelo poder hegemônico, a chamada Pax Americana.

\section{Os argumentos contra a Força Militar Unilateral}

Inovador na sua forma de apresentar o problema, Nye, tem os fatos ao seu favor. Isto porque o declínio da utilização do poder suave na política externa americana vem sendo medido e notado em diferentes setores. Por exemplo, tendo $o$ argumento da segurança nacional como principal justificativa, na sequência do 11 de Setembro, o governo dos Estados Unidos vem criando uma variedade de obstáculos para a concessão de vistos a estrangeiros interessados em estudar nas universidades do país. Em 2004, o número de estudantes de outros países que conseguiram se matricular caiu em relação a 2003. Em alguns casos, acadêmicos de nações do Oriente Médio que foram convidados para participar de congressos nas universidades americanas, acabaram recusando os convites pela impossibilidade de obterem o visto. ${ }^{6}$ A implicância da redução dessas formas de intercâmbio cultural é que ela prejudica o objetivo da política externa americana de propagar internacionalmente a democracia. A suposição é que estrangeiros que residem nos Estados Unidos durante um programa de estudos, absorvem no

${ }^{6}$ COURTEAU, Sarah. Diplomacy is in the Details. In: Wilson Quarterly, Summer 2005. p. 50-51. 
processo outros valores americanos, especialmente as liberdades individuais expressão, imprensa, religião - e que isso seria disseminado quando do retorno aos países de origem. Portanto, ao restringir esse canal de comunicação, os Estados Unidos estariam perdendo influência, e contribuindo para o aumento do sentimento antiamericano no resto do mundo.

Num artigo revelador sobre as consequências negativas da ausência do poder suave na condução das relaçôes internacionais, Martha Bayles, professora no Boston College, narra o papel desempenhado pela "A Voz da América" durante a Guerra Fria como ferramenta dos Estados Unidos para conter a expansão do comunismo. ${ }^{7}$ Financiada pelo governo americano, a emissora de rádio, nos anos 50, tinha uma audiência calculada em 100 milhões de ouvintes no mundo, incluindo 30 milhôes nos países da Cortina de Ferro, com transmissões em vários idiomas. Nos países do bloco socialista, incluindo a União Soviética, a elite intelectual, segundo a acadêmica, via rádio americana "como um tipo de brilho dourado no horizonte". Bayles relata também como a U.S. Information Agency (a antiga divisão de relaçōes públicas do executivo americano) tentou minimizar a crítica soviética à discriminação racial nos Estados Unidos por meio do patrocínio de shows, ao redor do mundo, de artistas americanos negros e consagrados pela sua arte como Louis Armstrong, Duke Ellington and Dizzy Gillespie.

No estágio atual do mundo pós-Guerra Fria, o Congresso efetuou cortes drásticos nos orçamentos de todos esses órgãos, e, por conta do mesmo racionamento de custos, centros culturais americanos em diversos países fecharam as portas. Segundo Bayles, os dados de um grupo de assessoria da Câmara de Deputados revelam que, em 2003, o número de pessoal empregado em programas de diplomacia pública nos Estados Unidos sofreu uma redução de $35 \%$, e o financiamento àquela atividade registrou um declínio de $25 \%$. Trata-se de mais um cerceamento dos canais de comunicação entre os Estados Unidos e o resto do mundo, em outras palavras, uma falta do poder suave na política exterior americana. Quando o mais importante contato de estrangeiros com os Estados Unidos é através de embaixadas e consulados construídos como bunkers, e diante da reação negativa à guerra no Iraque (especialmente com a revelação de maus tratos aos prisioneiros iraquianos), e na ausência de um esforço para disseminar os valores embutidos na Constituição americana, não é surpresa que esteja crescendo a antipatia aos Estados Unidos. ${ }^{8}$

Embora não empregue explicitamente o conceito de poder suave, preferindo trabalhar com a existência de um componente sedutor da cultura

\footnotetext{
7 BAYLES, Martha. Goodwill Hunting. In: Wilson Quarterly, Summer 2005. p. 46-56.

${ }^{8} \mathrm{O}$ que a autora considera extremamente problemático é que com o recuo da diplomacia pública americana e com a falta de um esforço governamental para promover os valores democráticos, o que o resto do mundo absorve e consome dos Estados Unidos é a chamada pop culture (música, filmes, videogames e websites) que, em muitos casos, é rejeitada pela própria sociedade americana pelo conteúdo leviano, pornográfico ou obsceno em algumas dessas atividades.
} 
americana (segundo ele mal utilizado pelo governo), Brzezinski sustenta que uma estratégia militar unilateral por si só não será capaz de dar conta de ideologias extremistas e açôes violentas por parte de grupos radicais, que constituem hoje um dos grandes desafios confrontando à hegemonia dos Estados Unidos. Como for, a origem polonesa do autor certamente o coloca em posição singular para analisar o impacto da utilização dos poderes duro e suave para a obtenção de objetivos da política internacional. Com um regime comunista imposto pela União Soviética a partir do final da Segunda Guerra Mundial, em 1945, e que se estendeu até o fim da década de 1980, a Polônia é, provavelmente, um dos casos mais contundentes para validar o êxito da combinação de poderes de coerção e persuasão dos Estados Unidos. Com uma população de aproximadamente 40 milhões, eminentemente católica e completamente identificada com os valores ocidentais, a Polônia se transformou num dos grandes alvos americanos na luta contra o comunismo durante a Guerra Fria. Enfrentando um governo imposto pela União Soviética, a sociedade civil polonesa, ao longo dos anos, e sempre amparada pela hierarquia da Igreja Católica do país, minou (não sem custos) o regime comunista. Sob o risco de ostracismo, detençôes e outras represálias, muitos poloneses se aliaram, clandestinamente, a grupos opositores ao sistema; estes receberam diversas formas de apoio do governo americano, incluindo recursos para o financiamento de atividades antigovernamentais, como publicações e midia; bolsas concedidas a opositores, para estudos em universidades americanas, e para alguns, a concessão de asilo e residência nos Estados Unidos.

E certamente o maior suporte americano à oposição polonesa foi dado ao sindicato Solidariedade, cujo líder, o eletricista Lech Walesa, seria eleito, posteriormente, presidente da Polônia pós-comunista. De fato, estudiosos da Guerra Fria tendem a ver na formação do Solidariedade nos anos 70, e nas lutas sindicais da década seguinte, como os fatores embrionários ou iniciantes dos subsequente eventos, como a queda do Muro de Berlim, em novembro de 1989, e a derrocada do comunismo e desintegração da União Soviética em 1991. Esse uso do poder suave, como Bayles recorda, foi particularmente intenso durante os dois mandatos do presidente Ronald Reagan, quando a diplomacia pública americana floresceu consideravelmente, com o orçamento da U.S. Information Agency crescendo quase o dobro em oito anos, para chegar a cerca de US\$900 milhões em 1989. Uma parte daqueles recursos financiou também outra ferramenta da diplomacia pública, a rádio Free Europe, sediada em Praga, cujas transmissões dirigidas aos países do bloco socialisita enfatizavam o apoio dos Estados Unidos aos grupos e cidadãos que se opunham ao regime comunista.

Esses instrumentos de poder suave, o qual inclui também o Plano Marshall para a reconstrução da Europa depois da Segunda Guerra, tiveram o suporte indispensável do poder duro, a Organização do Tratado do Atlântico Norte (Otan), a aliança de defesa entre América do Norte e Europa, na qual a maior 
contribuição em termos de equipamentos militares é feita pelo Estados Unidos? Para analistas é impossível minimizar o êxito dessa estratégia - dura e suave na política americana de contenção do comunismo direcionada ao continente europeu. Sendo na época, a outra superpotência igualmente munida de poderes duros e suaves, a União Soviética, entretanto, perdeu a batalha para a conquista dos coraçôes e mentes. ${ }^{10}$

Naturalmente não é possivel, ou pelos menos é arriscado, o estabelecimento de uma analogia total e perfeita entre a política contra o comunismo levada adiante pelo governo americano durante a Guerra Fria, e as políticas contra o terrorismo a partir do 11 de Setembro. Provavelmente, a maneira mais simples de invalidar a comparação é a constatação da natureza do inimigo: de um lado, durante a Guerra Fria, havia uma outra superpotência, a União Soviética, com poderes para coagir e persuadir; de outro lado, observamos, agora, a existência de grupos não governamentais, combatentes sem bandeira, e de certa forma invisíveis e com morfologia desconhecida. Mas não se pode negar que da mesma forma que por quase cinco décadas a luta contra o comunismo foi o eixo central da política exterior americana, e quando todas as ações tinham aquela meta como prioridade, agora a derrota do terrorismo assumiu aquele papel prioritário. Foi o próprio presidente George Bush quem expressou a centralidade do novo inimigo quando declarou o 11 de Setembro como um "evento transformador" da política externa dos Estados Unidos.

Uma questão crucial que enfrentamos então é se as armas para combater esse novo inimigo terão de ser diferentes das empregadas para combater o rival anterior. Em outras palavras, a política de contenção do comunismo na Guerra Fria oferece lições para as políticas antiterroristas no mundo da pós-Guerra Fria? Se é certo, como Nye observa, que o poder suave americano, através das idéias e outros instrumentos de persuasão, é o que finalmente diminuirá o apelo de grupos extremistas, impedindo-os de recrutar novos seguidores, a pergunta natural é por que a atual política exterior dos Estados Unidos dá prioridade ao poder duro? Apontar o dedo para o Partido Republicano - que

\footnotetext{
${ }^{9}$ Desenhado pelo Departmento de Estado Americano. O plano é considerado um dos maiores pacotes de assistência financeira da história. A idéia de ajudar a reconstrução dos países europeus destruídos pela guerra teve como objetivos - além da ajuda humanitária em si - a obtenção de estabilidade política e econômica, evitando o descontentamento social que poderia levar as sociedades européias a se aproximarem da ideologia comunista; outra meta era o fortalecimento do capitalismo.

10 São inúmeras nos Estados Unidos as análises que tentam explicar as causas que provocaram o fim da Guerra Fria, o colapso do comunismo como sistema de governo e a desintegração da União Soviética. Uma das correntes de opinião sustenta que a corrida armamentista entre as duas superpotências levou o Estado soviético à falência. Outros analistas observam que havia no sistema soviético uma série de falhas - políticas e econômicas - que debilitaram o regime (Goldestein e Pevehouse, p. 38). Uma outra explicação aponta para as reformas introduzidas pelo premier Mikhail Gorbatchov, a Pereistroiika (liberalização econômica) e a Glasnost (abertura política), e que ambas teriam escapado do controle do governo sovitético. Como for, vale a pena notar que os eventos - da maneira como ocorreram - não foram previstos pelos acadêmicos e tomadores de decisão nos Estados Unidos. Em outras palavras, não se esperava que o fim do regime comunista se daria como se deu de fato - em grande medida, pacificamente. Uma hipótese, embora sem evidência, é que os sucessivos governos americanos teriam superestimado o poder soviético.
} 
hoje controla o Executivo e o Legislativo americanos - pode ser uma resposta certa. Entretanto, é também simplista, já que outro Republicano, o presidente Reagan, embora tenha usado o poder duro contra a influência soviética na América Central, ao mesmo tempo entendeu - ou foi bem assessorado - sobre a importância do poder das idéias, refletido na decisão de injetar recursos nas campanhas governamentais de relações públicas. E o democrata Bill Clinton, que empregou o poder suave dos Estados Unidos para promover a idéia de cooperacão entre israelenses e palestinos, e tambem entre católicos e protestantes na Irlanda do Norte, não hesitou ao autorizar os ataques aéreos contra Belgrado para punir o então presidente sérvio, Slobodan Milosevic, pelas agressōes à população muçulmana em Kosovo.

As teorias clássicas das relações internacionais são ferramentas incompletas para avaliar essas indagações. ${ }^{11}$ Isso porque há diferença, por exemplo, entre a defesa da segurança nacional e a proteção dos interesses americanos no exterior (como prega o realismo de Henry Kissinger, o chamado realpolitik), e a imposição da democracia mundialmente, mesmo que seja com o uso da força, como propõem e atuam os neoconservadores na atual administração americana. ${ }^{12}$ Certos analistas, independentemente do marco teórico, preferem resumir a atual política externa americana como resultado do fenômeno da "presidência imperial", termo cunhado pelo historiador Arthur Schlesinger e aplicado aos presidentes americanos que agem sem limites diante da debilidade ou aquiescência do poder legislativo ${ }^{13}$.

A perspectiva neoconservadora, para alguns messiânica, e que segundo Brzezinski e Nye é uma das fontes do sentimento antiamericano no mundo, emergiu como política de governo em Setembro de 2002, com a divulgação da nova Estratégia de Segurança Nacional dos Estados Unidos, mais conhecida como a Doutrina Bush. O documento, que tem como ponto de partida a

\footnotetext{
11 São elas: a) o realismo, que enfatiza a segurança interna, a defesa dos interesses nacionais e a manutenção do poder como os objetivos essencias do Estado-nação nas suas interaçôes no sistema internacional. Religião, ideologia e fatores culturais não são elementos que pautam as ações de governo na visão dessa perspectiva; a cooperação internacional e as entidades multilaterais são de importância secundária; b) liberalismo e sua variante neoliberalismo colocam ênfase na importância da cooperação internacional e das organizações multilaterais como mecanismos para garantir a harmonia nas relações entre países; c) Radicalismo e suas variantes, incluindo a Teoria da Dependência, que ressaltam as assimetrias de poder no sistema internacional e que apontam o capitalismo como a fonte essencial de conflito entre as naçóes.

12 Não existe uma única definição para o termo neoconservador e para o conjunto das políticas neoconservadoras. Entretanto, como observa uma análise do jornal americano The Christian Science Monitor é possível apontar alguns elementos comuns nessa corrente: por exemplo, para promover os valores americanos no mundo, os Estados Unidos devem recorrer à força, se necessário; apoio incondicional à Israel; mudança de regime com o estabelecimento de democracias no Oriente Médio, começando pelo Iraque; pouco apego às organizações internacionais que, nessa visão, não são capazes de neutralizar às ameaças à segurança global; regimes abertamente hostis aos Estados Unidos, impondo ameaças, deveriam ser confontrados de maneira agressiva, e não apenas contidos ou apaziguados. Diferentemente dos neoconversadores, os simplesmente conservadores, por seu lado, são muito mais cautelosos com relação às intervençōes militares americanas. Além disso, os conservadores, ao invés da confrontação direta, dão preferências, nas relaçóes internacionais, às políticas de contenção e à détente.

13 SCHLESINGER, Arthur. The Imperial Presidency. New York: Replica Books, 1998.
} 
manutenção da hegemonia americana e as responsabilidades associadas a ela a promoção das liberdades política e econômica - imediatamente se transformou em polêmica pela introdução da possibilidade da preempção, de parte dos Estados Unidos, para lidar com ameaças potenciais. É sabido que a comunidade internacional é capaz de digerir um ataque de preempção, que ocorre quando, dispondo de evidência concreta de que será aniquilado por um país $\mathrm{X}$, o país $\mathrm{Y}$ se antecipa e ataca $X$. Mas, não há espaço no direito internacional para uma ação preventiva, na qual $\mathrm{Y}$ ataca $\mathrm{X}$ com base apenas numa suposta ameaça, intangível e talvez meramente especulativa.

Entre preempção e prevenção existe uma barreira que é exatamente a que separa as noções da guerra justa e da guerra injusta, cujos critérios articulados no passado por Tomás de Aquino (1225-1274), ${ }^{14}$ e Hugo Grotious (15831645), ${ }^{15}$ continuam pautando as relações políticas internacionais na atualidade. $\mathrm{Na}$ ausência de uma ameaça iminente, a guerra do Iraque cai na categoria de preventiva, e a posição do governo Bush qualificando a ação militar como parte da luta contra o terrorismo enfrenta as vozes discordantes nos Estados Unidos que não vêm essa conexão. De fato, o ataque preventivo no Iraque tende a ser visto como uma anomalia ${ }^{16}$ na política exterior americana, embora, vale a pena notar, a invasão norte-americana no Panamá, em 1989, que poderia entrar na mesma categoria. Como for, o fato é que presidentes anteriores não tinham na prevenção uma opção estratégica. Por exemplo, mesmo consciente da ameaça japonesa na Segunda Guerra, Franklin Roosevelt, evitou atacar o Japão em primeiro lugar e, posteriomente, a base americana de Pearl Harbour, no Pacífico, foi destruida pelos japoneses, em 7 de dezembro de 1941. E o sucessor, Harry Truman, confirmou a linha de Roosevelt quando declarou que "nós não acreditamos na guerra preventiva. Tal guerra é a arma dos ditadores, e não das sociedades democráticas". ${ }^{17}$

Nessa linha de pensamento, é interessante observar que o envolvimento americano no Afeganistão, onde mais de 10 mil soldados e outras tropas estrangeiras estão nos campos de batalha, na chamada guerra contra o terrorismo recebe uma atenção menor nessas análises. Isso pode ser resultado do entendimento dos autores, assim como de outros na comunidade internacional, incluindo as Nações Unidas, de que a intervenção armada iniciada em outubro de 2001, para depor o Taleban (o grupo que estava no poder no Afeganistão), tem legitimidade no Direito Internacional. Dado que o documento de fundação

\footnotetext{
14 AQUINAS, Thomas. Summa Theologicae, Part II. Benziger Bros, 1947.

15 GROTIUS, Hugo. On the Law of War and Peace. (Trans. A.C. Campbell). London, 1814.

16 É considerado uma anomalia porque ocorre como resultado de uma política oficial, articulada pela primera vez no documento "Estratégia de Segurança Nacional dos Estados Unidos”, ou simplesmente a Doutrina Bush. Anteriormente, intervenções militares como medida de prevenção não eram oficialmente reconhecidas como parte da estrategia americana, embora tenha ocorrido no Panamá em 1989, em Granada, 1984 e na República Domincan, 1965. Nesses casos, a justificativa americana foi que aqueles regimes representavam uma ameaça direta aos interesses dos Estados Unidos na América Latina e Caribe. 17 HOOK, Steven. U.S. Foreign Policy: The Paradox of World Power. Washington DC: CQ Press, 2005. p. 311.
} 
das Nações Unidas garante a cada país-membro o direito de auto-defesa, e de resposta no caso de ser atacado, o uso da força no Afeganistão estaria justificado pelas ações terroristas de 11 de Setembro, perpetradas por um grupo sob proteção do então governo afegão. Enquanto defendem a necessidade de ações contra o terrorismo, ressaltando o dever da superpotência de combatê-lo, a preocupação, entretanto, é como, e com quais instrumentos, assim como quais as consequências para os Estados Unidos, ao adotar uma opção em detrimento de outra.

Relacionado aos riscos do uso dessa estratégia militar com o principal instrumento para lidar com a ameaça representada pelo terrorismo, está o problema do unilateralismo que vem marcando a política externa do atual governo americano. Em vários temas de alcance global, como a proteção ambiental e dos direitos humanos, onde a magnitude dos problemas e o caráter interdependente dos mesmos requerem ações compartilhadas, os Estados Unidos têm sido notados pela ausência, como ficou claro na rejeição da Convenção de Kyoto e do Tribunal Penal Internacional. ${ }^{18}$ A necessidade de defender os interesses econômicos das empresas americanas e de assegurar a soberania nacional foram os argumentos apresentados pelo governo Bush para justificar a não participação dos Estados Unidos nesses acordos multilaterais. São justificativas de curto prazo que encontraram apoio em certos setores da sociedade americana, mas que no longo prazo, representam uma contradição, pois degradação ambiental, escassez de recursos naturais, e tensões geradas pelo desrepeito aos direitos humanos certamente não contribuem para a estabilidade global buscada pelo poder hegemônico. Considerando outra vez a Teoria da Estabilidade Hegemônica que pressupõe a necessidade de uma nação dominante para estabelecer uma ordem internacional, é natural indagar sobre a eficácia de acordos multilaterais, como os mencionados, em que o poder hegemônico é ausente.

\section{Conclusão: mudar de rumo para salvar a hegemonia?}

Assim, parece claro que a falta de cooperação da superpotência não somente prejudica os esforços para lidar com problemas globais, como também prejudica seus próprios interesses. Enquanto a promoção da democracia, respeito aos direitos humanos e mercados livres - as metas definidas pelo governo americano como os norteadores da política externa - são objetivos louváveis, provavelmente universais, e compatíveis, o problema para os atuais críticos da política exterior americana se resume à forma que os mesmos estão sendo buscados. Num tom

\footnotetext{
18 Dois acordos de cooperação multilateral rejeitados pelo governo de George W. Bush. A Convenção de Kyoto estabelece as ações a serem seguidas pelos países signatários para combater o efeito estufa, a elevação gradativa da temperatura da Terra, em consequência da atividade industrial e da liberação de gases tóxicos na atmosfera pela queima de combustíveis. O Tribunal Penal Internacional (International Criminal Court) é outra peça do direito international, apoiada por vários governos, visando o indiciamento de indivíduos envolvidos em crimes contra a humanidade.
} 
similar às análises de Brzezinski e Nye, outro acadêmico, George Perkovich, vice-presidente do Carnegie Endowment for International Peace, uma organização sem fins lucrativos dedicada às pesquisa e análises políticoeconômicas, com sede em Washington, alertou para as limitaçōes de uma política que enfatiza liberdade - política e econômica - mas que negligencia a questão da justiça. "O que é problemático na atual obsessão dos Estados Unidos com liberdade, não é a liberdade, mas a obsessão" disse ele, reiterando as ligações conhecidas entre desigualdades, injustiça e instabilidade internacional. $\mathrm{O}$ autor considera a ideologia da liberdade promovida pelos Estados Unidos insuficiente para lidar com as consequências das disparidades sociais, observando que o problema "não é o mercado livre, mas sim a falta de atenção à maneira como os ricos e poderosos modelam as regras do mercado em seu próprio benefício". ${ }^{19}$

Sem diferir, portanto, dos preceitos centrais da Teoria da Estabilidade Hegemônica, não são poucas as vozes urgindo uma correção de rumo da política exterior americana. Não se questiona, portanto, o valor intrínseco da hegemonia, ou seja, se boa ou má, e em qualquer dos casos, para quem. Trata-se de um debate, que pela sua natureza é de difícil resolução. Mesmo porque um mundo globalizado e indeterdependente é no mínimo arriscada a hipótese de que por sua posição hegemônica, a superpotência estaria colhendo absolutamente todos os benefícios. De fato, sendo o país o defensor e promotor número um do capitalismo e da globalização dos mercados, os Estados Unidos, ou mais precisamente a classe trabalhadora americana, vem sentindo os efeitos negativos dessa ordem econômica. A evidência está nos dados do mercado de trabalho americano, onde empregos eliminados estão sendo transferidos para a Índia e a China, nações cada vez mais competitivas no mercado internacional. ${ }^{20}$

Deixando de lado o julgamento sobre o valor da hegemonia, o que resta é a constatação de que, como um processo histórico, a mesma é uma condição inevitável. Poderes hegemônicos surgiram e floresceram no passado, como os impérios romano e britânico, e ambos enfrentaram os que desafiavam seu poder. E da mesma forma que é inevitável, a hegemonia é também uma condição passageira, como bem recorda Brzezinski em seu trabalho mais recente, como a história demonstra, e como já foi amplamente analisado há quase uma década por Paul Kennedy, outro acadêmico da Universidade Harvard. ${ }^{21}$ Sem aderir ao conceito clássico do imperialismo, o atual poder hegemônico, baseado num

\footnotetext{
19 PERKOVICH, George. Giving Justice Its Due. Foreign Affairs, July-August 2005. p. 79-93.

${ }^{20} \mathrm{Na}$ produção literária acadêmica nos Estados Unidos encontramos análises discutindo o impacto da crescente globalização e interdepedência sobre a hegemonia americana. Nota-se, por exemplo, uma lenta, mas aparentemente irreversível, mudança do eixo de poder econômico, do Ocidente para o Oriente, com o fortalecimento das economias da China e da Índia. Essa mudança de pêndulo seria um dos indicadores do declínio da hegemonia dos Estados Unidos.

${ }^{21}$ No trabalho The Rise and Fall of the Great Powers, Kennedy introduz o conceito de imperial overstretch para explicar o declínio dos poderes imperiais. Quando uma potência mundial se expande em excesso (overstretch), incorrendo em atividades altamente custosas ao redor do mundo, a mesma começaria a enfrentar debilidades internas que levariam ao declínio da hegemonia.
} 
governo constitutional, republicano e representativo, com uma sociedade dinâmica e pluralista, pode certamente manter a mesma posição dominante recorrendo simplesmente a seu incontestável poderio militar. Mas a que custo?

Recebido em 12 de setembro de 2005 Aprovado em 20 de outubro de 2005

\section{Referências bibliográficas}

BRZEZINSKI, Zbigniew. The Choice: Global Domination or Global Leadership. New York: Basic Books, 2004.

GOLDSTEIN, Joshua \& Jon PEVEHOUSE. International Relations. New York: Pearson/ Longman, 2006.

HOOK, Steven. U.S. Foreign Policy: The Paradox of World Power. Washington DC: CQ Press, 2005. GOLDSTEIN, Joshua \& Jon PEVEHOUSE. International Relations. New York: Pearson/ Longman, 2006.

HOOK, Steven. U.S. Foreign Policy: The Paradox of World Power. Washington DC: CQ Press, 2005. KENNEDY, Paul. The Rise and Fall of the Great Powers. New York: Vintage Books, 1987.

NYE, Joseph. The Paradox of American Power: Why the Worldis Only Superpower Canit Go It Alone. Oxford and New York: Oxford University Press, 2003.

NYE, Joseph. Soft Power: The Means to Success in World Politics. New York: Public Affairs Press, 2004.

SCHLESINGER, Arthur. The Imperial Presidency. New York: Replica Books, 1998.

\section{Resumo}

Este artigo toma como referência analítica a teoria da estabilidade hegemônica como ponto de partida para o exame dos objetivos buscados por uma corrente crítica nos Estados Unidos que propõe um mudança de rumo na condução da atual política externa americana. Os conceitos de poder duro e de poder suave, e as implicações de ambos, são discutidos dentro do contexto das ações internacionais dos Estados Unidos, contrapondo as prioridades da Guerra Fria com os novos desafios da era pós-Guerra Fria, a partir dos atentados de 11 de Setembro e a guerra no Iraque.

\section{Abstract}

This article employs the theory of hegemonic stability as the analytical tool and the starting point for the examination of the goals sought by a stream of critics in the United States who are proposing changes in the conduction of the current American foreign policy. The concepts of hard power and soft power, and the implications of both, are discussed in the context of external actions of the United States, with a contrast between the Cold War priorities and the new post-Cold War challenges, in the aftermath of the September 11 attacks and the war in Iraq.

Palavras-chave: Estados Unidos; Política Exterior; Hegemonia; Poder Duro; Poder Suave; Unilateralismo.

Key words: United States; Foreign Policy; Hegemony; Hard Power; Soft Power; Unilateralism. 